\title{
ASPECTOS FENOLÓGICOS DE SEIS ESPÉCIES VEGETAIS EM MATAS DE GALERIA DO DISTRITO FEDERAL ${ }^{1}$
}

\author{
NEIVA BEATRIZ ANTUNES² e JOSÉ FELIPE RIBEIRO ${ }^{3}$
}

\begin{abstract}
RESUMO - A fenologia de Vochysia piramidalis, Tapirira guianensis, Talauma ovata, Tococa formicaria, Miconia pseudonervosa e Miconia chamissois foi acompanhada de abril de 1994 a setembro de 1995, em dez indivíduos de cada espécie. Todas foram perenifólias, sugerindo relação com a presença de água no solo. Vochysia piramidalis e T. guianensis apresentaram padrão de floração atrasada em relação ao início das chuvas; T. ovata, T. formicaria e M. pseudonervosa, floração precoce; e M. chamissois, floração tardia. Quanto à duração da floração, M. pseudonervosa e T. formicaria apresentaram período longo e $V$. piramidalis, T. ovata, T. guianensis e M. chamissois, período curto. Vochysia piramidalis revelou padrão de dispersão anemocórico, com curto período de formação e maturação dos frutos. As demais, padrão zoocórico. Miconia pseudonervosa apresentou maturação variando dentro e entre indivíduos. Talauma ovata exibiu frutos imaturos por período extenso, mas com maturação rápida e simultânea no mesmo indivíduo. A produção foi abundante em $T$. guianensis, com maturação simultânea dentro do mesmo indivíduo e intervalos curtos entre os períodos reprodutivos. T. formicaria e M. chamissois apresentaram um período relativamente curto de frutificação, porém com maturação não-simultânea dentro do mesmo indivíduo. A frutificação das espécies zoocóricas foi durante o período chuvoso, coincidindo com o período de dispersão de animais.
\end{abstract}

Termos para indexação: mata ciliar, fenologia reprodutiva, fenologia vegetativa.

PHENOLOGICAL ASPECTS OF SIX GALLERY FOREST SPECIES OF THE FEDERAL DISTRICT IN BRAZIL

\begin{abstract}
The phenology of Vochysia piramidalis, Tapirira guianensis, Talauma ovata, Tococa formicaria, Miconia pseudonervosa and Miconia chamissois were observed weekly, from April/94 to September/95, on ten individuals of each specie. All species presented perennial leaves maybe due to soil water availability. According to the beginning of the rainy season, V. piramidalis and T. guianensis presented delayed flowering, T. ovata, T. formicaria and M. pseudonervosa precocious flowering, while $M$. chamissois was classified as late. Miconia pseudonervosa and T. formicaria showed a long period of flowering and V. piramidalis, T. ovata, T. guianensis and M. chamissois a short one. Vochysia piramidalis showed anemochorous dispersal pattern and all the other five species showed zoochorous. Miconia pseudonervosa showed ripeness varying among and within plant. Talauma ovata also showed a long period of immature fruits, but with simultaneous and quick ripening within the same tree. Tapirira guianensis presented a large period of fruit production, simultaneous ripeness and short intervals between reproductive periods. Tococa formicaria and M. chamissois showed a non-simultaneous short fruiting period within the same tree. In general, the zoocoricous species showed fruiting period within the rainy season, with corresponding animal dispersal period.
\end{abstract}

Index terms: riparian vegetation, phenology, reproductive patterns.

${ }^{1}$ Aceito para publicação em 28 de julho de 1998. Extraído da Dissertação de Mestrado da primeira autora apresentada à UnB, Brasília, DF.

${ }^{2}$ Bióloga M.Sc., Rua Pedro Urias da Silva, 268 Luizote II, CEP 38414-380 Uberlândia, MG.

${ }^{3}$ Biólogo, Ph.D., Embrapa-Centro de Pesquisa Agropecuária dos Cerrados (CPAC), Caixa Postal 08223, CEP 73301-970 Planaltina, DF.E-mail: felipe@cpac.embrapa.br

\section{INTRODUÇÃO}

A fenologia estuda a ocorrência de eventos biológicos periódicos e as causas de sua ocorrência, em relação a fatores bióticos e abióticos, e a inter-relação entre fases caracterizadas por esses eventos numa mesma e em diferentes espécies (Lieth, 
1974). Mediante estudos fenológicos é possível prever a época de reprodução, deciduidade e ciclo de crescimento vegetativo, parâmetros que podem ser utilizados para o manejo adequado da flora (Ribeiro \& Castro, 1986). São quatro as principais fenofases consideradas na maioria dos estudos em plantas: queda de folhas, folhas novas, floração e frutificação. De maneira geral, a queda de folhas parece estar associada com fatores climáticos, como a pluviosidade. Autores como Rizzo et al. (1971), Barros \& Caldas (1980), Mantovani \& Martins (1988), Oliveira (1991) e Arrigoni (1993) mostraram que no Cerrado Sentido Restrito (SR) (Ribeiro \& Walter, 1998) a caducifolia acontece no período seco (maio a agosto), mas Ribeiro et al. (1982) também observaram que o surgimento de folhas novas nem sempre está sincronizado com o início das chuvas.

Observações fenológicas permitem ainda a caracterização de padrões reprodutivos. Janzen (1975) ressalta que nas florestas tropicais são freqüentes os padrões com florescimento e frutificação anual das espécies. Em uma determinada comunidade, geralmente a floração se distribui ao longo do ano, de modo que haja fornecimento de néctar ou pólen para os diversos polinizadores. Vários estudos relacionaram tempo de floração com polinizadores (Janzen, 1967; Frankie et al., 1974b; Stiles, 1977). Janzen (1980) afirma que a produção sincronizada de flores de espécies diferentes, por curto período de tempo, também poderia atrair a atenção de polinizadores menos especializados. Já as espécies cujo florescimento ocorre de forma assincrônica atrairiam polinizadores especialistas. PiñaRodrigues \& Piratelli (1993) acrescentaram que no âmbito de espécie ocorre variação da época de florescimento de acordo com o local e as condições climáticas.

Pressões seletivas podem ser exercidas por dispersores, favorecendo os indivíduos que frutificam em períodos em que os dispersores são mais abundantes (Snow, 1965, 1971; Gentry, 1974). Stiles (1980) mostra resultados que sugerem que em espécies com sementes dispersas por aves, a época de formação e maturação dos frutos é resultante das pressões seletivas. Nesse caso, sincronismo na floração e na frutificação poderia trazer a vantagem de atrair polinizadores e dispersores de sementes. Além disso, a frutificação e a germinação sincronizadas poderiam assegurar a sobrevivência de sementes e plântulas por saciação do predador (Janzen, 1975). Esse autor também considera que a seleção natural favoreceria as espécies que produzem frutos quando as condições ambientais fossem propícias à dispersão, germinação e posterior estabelecimento das plântulas. Dessa forma, sementes anemocóricas seriam produzidas na estação seca, quando as condições poderiam favorecer a sua dispersão. Janzen (1967) já havia sugerido que as espécies zoocóricas produziriam frutos na estação chuvosa. Mantovani \& Martins (1988) acrescentaram que na estação chuvosa os frutos teriam maior duração e seriam mais atraentes aos dispersores.

Nas formações florestais, em regiões onde a estação seca é amena, as plantas concentram a frutificação no final da estação chuvosa, e onde a estação seca é mais severa, a concentração da frutificação ocorre no início dessa estação (Frankie et al., 1974a). Já Foster (1980) afirmou que em áreas com estação seca intermediária, os picos de frutificação ocorrem em ambas as épocas. Em áreas de Cerrado, onde existe uma estação seca e uma estação chuvosa bem definidas, é comum ocorrer floração durante a seca (Ferri, 1977) e a abertura dos frutos coincidir com as primeiras chuvas, como no caso de Magonia pubescens (Joly \& Felippe, 1980), de gêneros como Dalbergia, Stryphnodendron, Qualea, Kielmeyera e Dimorphandra (Barros \& Caldas, 1980) e de espécies zoocóricas em geral (Oliveira, 1991). Já a frutificação de espécies com dispersão anemocórica é mais comum durante a estação seca (Gottsberger \& Silberbauer-Gottsberger, 1983; Mantovani \& Martins, 1988). Desse modo, as espécies parecem concentrar a floração e a frutificação em períodos variados, mas que maximizem a polinização das flores, a dispersão das sementes e que atendam às suas exigências quanto à germinação, ao estabelecimento e ao desenvolvimento de plântulas. Entretanto, modificações nas condições ambientais podem alterar padrões reprodutivos esperados. Espécies sucessionais tardias, por exemplo, podem florescer ou frutificar precocemente se ocorrerem em locais perturbados (Ng, 1966). 
Oliveira \& Moreira (1992) apontaram que as matas de galeria da região do Cerrado foram pouco investigadas sobre a fenologia de suas espécies. Seria necessário esclarecer se as matas de galeria realmente funcionam como refúgio para animais na época seca ou se a concentração de frutos no período chuvoso estaria associada à maior quantidade e atividade de dispersores nas matas em relação ao Cerrado, ou mesmo se a periodicidade de eventos fenológicos das espécies das matas de galeria coincide com as mudanças sazonais típicas da Região do Cerrado.

Gottsberger \& Silberbauer-Gottsberger (1983) e Oliveira (1991) sugeriram que a concentração da frutificação ocorreria no período chuvoso, pelo aumento da quantidade e da atividade dos vetores animais, enquanto Oliveira (1998) sugeriu que essa concentração ocorreria na estação seca, por considerar que as matas de galeria funcionariam como refúgio para alguns animais durante esse período.

Este estudo teve como objetivo caracterizar o comportamento fenológico em relação à queda de folhas, foliação, floração e frutificação de seis espécies de matas de galeria da região do Cerrado e relacioná-las com parâmetros ambientais como temperatura média mensal, precipitação pluvial mensal da região e identificar síndromes de dispersão das espécies estudadas.

\section{MATERIAL E MÉTODOS}

As espécies escolhidas para o estudo foram três arbustos: Miconia chamissois Naud., Miconia pseudonervosa Cogn. e Tococa formicaria Mart. (Melastomataceae), e três árvores: Talauma ovata St.Hil. (Magnoliaceae), Tapirira guianensis Aubl. (Anacardiaceae) e Vochysia piramidalis Mart. (Vochysiaceae), todas fitossociologicamente importantes em matas de galeria do Distrito Federal. O material botânico dessas espécies foi coletado e depositado no herbário da Universidade de Brasília (UnB) com os números NB 67890, NB 67903, NO 67911 e NO 67920.

\section{Descrição das áreas}

Duas matas de galeria que margeiam córregos de uma mesma bacia hidrográfica foram utilizadas para o estudo. Ambas as matas estão localizadas em Planaltina, DF, na região central do Brasil, com altitude de $1.000 \mathrm{~m}$, latitude $15^{\circ} 35^{\prime} 30^{\prime \prime} \mathrm{S}$ e longitude $47^{\circ} 42^{\prime} 30^{\prime \prime} \mathrm{W}$. Às margens do córrego Sarandi, numa mata de galeria não-inundável preservada pela Embrapa-Centro de Pesquisa Agropecuária dos Cerrados (CPAC), encontram-se as populações das espécies M. chamissois, M. pseudonervosa, T. guianensis, T. formicaria e $V$. piramidalis, enquanto a população de $T$. ovata encontra-se numa mata de galeria inundável do córrego da Piteira, na área urbana de Planaltina, DF. O clima da região é do tipo Aw, de acordo com as categorias de Köppen, onde se definem nitidamente uma estação seca (geralmente de abril a setembro) e outra chuvosa (outubro a março). A precipitação pluvial média anual (média de 20 anos) (Fig. 1) é 1.511,2 mm, e as médias de temperaturas máximas e mínimas são de $27,4^{\circ} \mathrm{C}$ e $16,3^{\circ} \mathrm{C}$, respectivamente.

\section{Métodos}

Entre vários indivíduos adultos com estado fitossanitário satisfatório e evidência de floração anterior, foram escolhidos aleatoriamente dez de M. chamissois, M. pseudonervosa, T. formicaria, T. guianensis, V. piramidalis e $T$. ovata, com médias de altura de $2,35 \mathrm{~m}$, 2,54 m, 1,55 m, 18,0 m, 9,56 m e 15,0 m, respectivamente, e identificados com placas de alumínio. As observações fo-

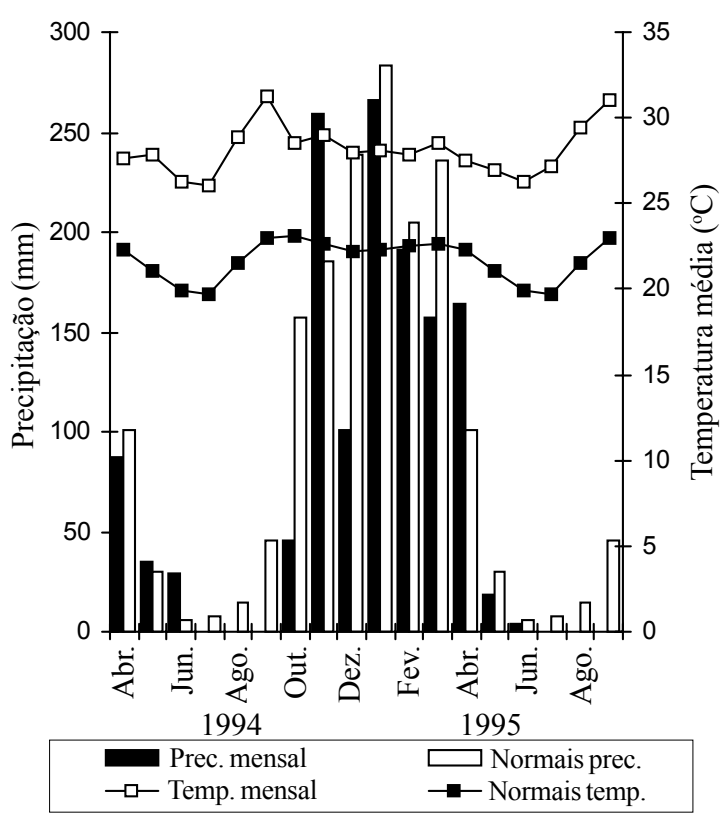

FIG. 1. Precipitação pluvial e temperaturas médias das áreas de estudo, normais pluviométricas e de temperaturas médias dos últimos 20 anos. Planaltina, DF, 1995. 
ram semanais, com a utilização de binóculo do tipo BG M-50 (aumento 4 x 50). A presença ou a ausência das características das fenofases foram anotadas em fichas de acompanhamento, de abril de 1994 a setembro de 1995. Os períodos de floração e de frutificação foram comparados com informações obtidas nos registros dos herbários da UnB e da Universidade Federal de Uberlândia. Para determinação da duração dos períodos de floração e frutificação foram classificados como: períodos curtos - até cinco meses de duração do evento, e períodos longos - acima de seis meses de duração do evento.

\section{RESULTADOS E DISCUSSÃO}

\section{Produção de folhas novas e queda de folhas}

Todas as espécies estudadas apresentaram comportamento perenifólio, apenas com uma pequena concentração de perda de folhas verificada em T. formicaria (arbusto) e V. piramidalis (Fig. 2) coincidente com a época seca do ano (maio/1994 e 1995). Nessa ocasião ocorreram os índices pluviométricos mais baixos $(<30 \mathrm{~mm})$ e as temperaturas em torno de $22^{\circ} \mathrm{C}$, marcando o começo de estações secas relativamente severas na região do Distrito Federal. O comportamento perenifólio nas matas de galeria estudadas, contrastou com o das espécies dos cerrados contíguos, que perderam as folhas durante a época mais seca do ano (Rizzo et al., 1971; Barros \& Caldas, 1980; Mantovani \& Martins, 1988; Oliveira, 1991; Arrigoni, 1993).

Trabalhando em áreas de Cerrado de diversas regiões do país, Barros \& Caldas (1980), Joly \& Felippe (1980), Ribeiro et al. (1982), Araújo et al. (1987) e Mantovani \& Martins (1988), verificaram produção de folhas novas no final da estação seca e no início da estação chuvosa. Esse também foi um aspecto contrastante com o observado neste estudo, já que nas espécies $T$. guianensis, T. formicaria, $M$. pseudonervosa e $M$. chamissois, as folhas novas surgiram na época seca (Fig. 2). O padrão de deciduidade foliar tanto em relação às árvores quanto aos arbustos estudados parece não sofrer interferência direta da ausência de chuvas no período seco.

\section{Floração}

Os períodos de florescimento dessas espécies, registrados em material botânico do herbário da
UnB coletados nos Estados de Goiás, Mato Grosso, Mato Grosso do Sul, Minas Gerais, São Paulo, Bahia e no Distrito Federal, foram confrontados com a época de floração das espécies do presente estudo e, em geral, concordaram com as observações realizadas. O intervalo de 18 meses (abril de 1994 a setembro de 1995) escolhido para este estudo (duas estações secas e uma chuvosa) permitiu observar duas florações de $M$. pseudonervosa, $M$. chamissois e $T$. formicaria, enquanto a espécie T. ovata apresentou apenas uma floração. $\mathrm{Na}$ $V$. piramidalis e $T$. guianensis, no mesmo período de coleta de dados, também só foi possível observar uma floração.

Sarmiento \& Monastério (1983) classificaram a floração de espécies das savanas em precoce, atrasada e tardia em relação ao início da estação chuvosa. Pelos resultados aqui apresentados as espécies arbóreas $T$. guianensis e $V$. piramidalis foram classificadas como atrasadas e $T$. ovata, assim como as espécies arbustivas $T$. formicaria e M. pseudonervosa apresentaram padrão precoce, com floração iniciando durante a estação seca e finalizando na estação chuvosa. A outra espécie arbustiva, $M$. chamissois, foi a única que apresentou o padrão de floração tardia, florescendo durante a estação seca. Frankie et al. (1974a) encontraram em uma floresta decídua na Costa Rica que a floração naquela comunidade poderia acontecer o ano todo, mas com um pico coincidente com o surgimento das folhas novas no início da estação seca. Oliveira (1991) também encontrou o mesmo padrão em uma comunidade de Cerrado (SR). Nenhuma das espécies arbóreas aqui estudadas apresentou esse padrão. Todas elas tiveram pico de floração durante a estação chuvosa (Fig. 2). Apesar de essas espécies serem fitossociologicamente importantes nas matas de galeria, os resultados não podem ainda ser extrapolados para toda a comunidade. O padrão acima descrito por Frankie et al. (1974a) e confirmado por Oliveira (1991) foi encontrado em fitofisionomias decíduas. Já a mata de galeria pode ser considerada uma das poucas fitofisionomias da região que encontra-se na categoria de "sempre-verde". Tal aspecto deve estar correlacionado com a maior disponibilidade de água, que por sua vez poderia estar originando pa- 

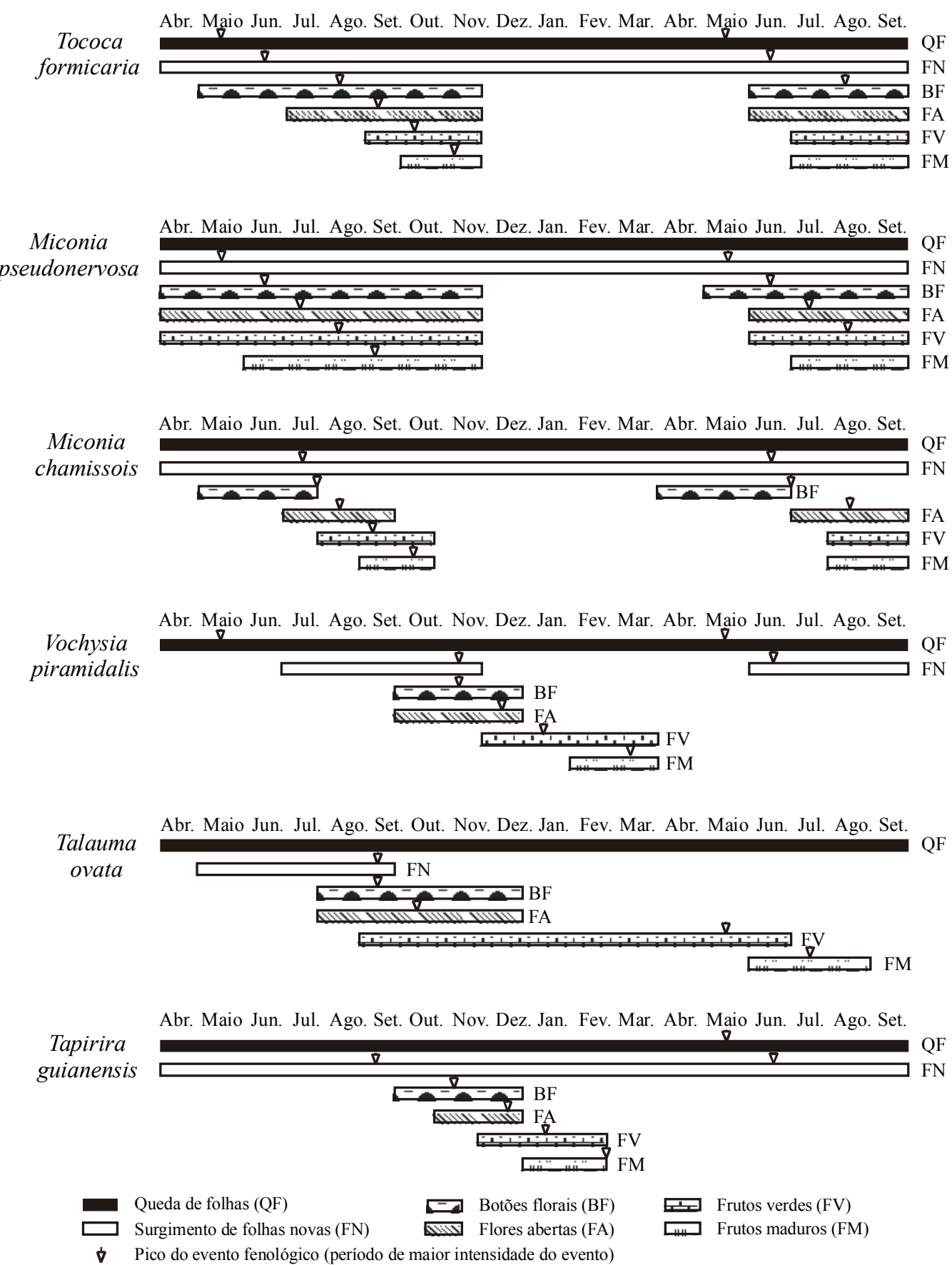

FIG. 2. Fenograma de seis espécies em matas de galeria do Distrito Federal no período de abril de 1994 a setembro de 1995. 
drões fenológicos diferenciados das fitofisionomias mais secas adjacentes à mata. Trabalhando em cerrados menos secos no limite sul (MogiGuaçu, SP), Mantovani (1983) também verificou um pico de floração no período chuvoso. Para Mantovani \& Martins (1988), a maior concentração de espécies florindo na época chuvosa estaria relacionada não só com o alto índice de pluviosidade e umidade relativa, mas também com temperaturas mais altas e fotoperíodos mais longos.

Diferentes durações no período de ocorrência de floração também foram encontradas entre as espécies estudadas (Tabela 1). O longo período de florescimento, com início na estação seca (maiojunho/1994) e término no início das chuvas (outubro-novembro/1994) apresentado por M. pseudonervosa e T. formicaria (Fig. 2), também foi encontrado em outras espécies por IbarraManríquez \& Oyama (1992). Entretanto, somente $16,5 \%$ das 139 espécies da floresta tropical mexicana estudada por esses autores apresentaram o mesmo padrão, das quais apenas $3,6 \%$ tiveram um padrão de florescimento desde a estação seca até o período chuvoso. Os mesmos autores verificaram que no restante das espécies que tiveram florescimento longo $(12,9 \%)$ a época de floração foi inversa, iniciando na época chuvosa e terminando na seca. Para a fitofisionomia Cerrado (SR), Oliveira (1991) discutiu que a fenologia da floração foi diferente dentro e entre grupos de plantas com o mesmo sistema de polinização. $\mathrm{O}$ autor mostrou que no Cerrado existem plantas em flor durante todo $\mathrm{o}$ ano e nenhum polinizador em particular poderia ser aparentemente limitado pela floração condicionada pela estação climática. Entretanto, esse mesmo estudo mostrou que algumas espécies apresentaram o período de floração restringida. No presente trabalho, todas as espécies arbóreas (V. piramidalis, $T$. guianensis, $T$. ovata) e o arbusto $M$. chamissois apresentaram período curto de floração (floração restringida), ocorrendo principalmente durante a estação chuvosa (outubro a dezembro/1994). Além disso, Vochysia piramidalis e T. guianensis tiveram floração similar ao padrão geral observado por Oliveira \& Gibbs (1994) com seis espécies de Vochysia em áreas de Cerrado e mata de galeria do Jardim Botânico de Brasília. En-

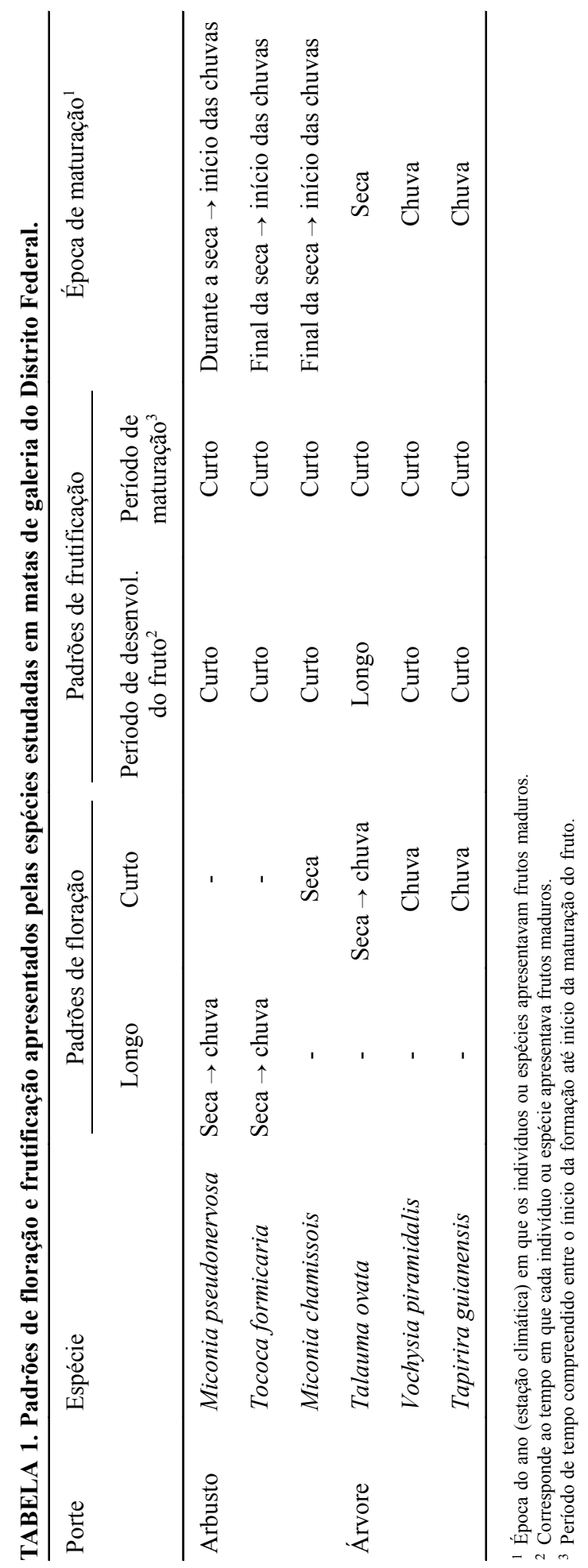


tretanto, os mesmos autores encontraram um período um pouco diferente, pois aqui $V$. piramidalis floresceu durante a transição seca-chuva (setembro a outubro).

Piña-Rodrigues \& Piratelli (1993) associaram a floração na época seca com condições propícias à dispersão do pólen em espécies anemófilas. As espécies de Cerrado (SR), Campomanesia rufa (Arrigoni, 1993) e Magonia pubescens (Joly \& Felippe, 1980), são exemplos de espécies que tipicamente produzem flores na estação seca. No presente trabalho, a espécie $T$. ovata também iniciou a floração na estação seca (agosto/1994), mas terminou durante o período chuvoso (dezembro/1994). O pico de botões florais, entretanto, foi observado em setembro, época extremamente seca na região. Esse não foi um comportamento típico das florestas tropicais estudadas por Ibarra-Manríquez \& Oyama (1992) no México, pois apenas 5\% das espécies estavam com flores na época seca do ano. Assim como as espécies arbóreas, M. chamissois (arbusto) também apresentou floração curta, mas concentrada apenas na estação seca (maio a setembro/1994 e 1995). O pico de produção de botões florais foi na época mais seca do ano (princípio de agosto), quando a pluviosidade foi nula e a temperatura média foi de $21,4^{\circ} \mathrm{C}$ (Fig. 1). Aparentemente esse evento parece não estar associado à maior disponibilidade de água nas matas de galeria, já que Ferri (1977), Aoki \& Santos (1980), IbarraManríquez \& Oyama (1992) e Piña-Rodrigues \& Piratelli (1993) encontraram várias espécies florindo nessa mesma época do ano no Cerrado.

\section{Frutificação}

A época de frutificação de todas as espécies deste estudo foi comparada com a época de ocorrência de frutos verificada nos materiais botânicos dos herbários da UnB e da Universidade Federal de Uberlândia. Como na floração, pareceu haver uma pequena variação em torno do período observado no presente estudo, de acordo com as diversas área de ocorrência da planta. A espécie M. pseudonervosa, por exemplo, apresentou na Bahia e em dois locais diferentes de Mato Grosso, a formação e a maturação dos frutos cerca de 30 dias antes que em outras regiões de Goiás, Distrito Federal e Maranhão.
Oliveira (1991) estudando uma comunidade de plantas de cerrado, verificou que apesar de a frutificação ser anual e contínua ao longo do ano, foi comum encontrar variações individuais na qualidade dos frutos e intensidade da frutificação. De maneira geral, o mesmo padrão foi encontrado nas matas de galeria estudadas. Da mesma forma, IbarraManríquez \& Oyama (1992) também notaram variações no período de frutificação de 139 espécies numa floresta tropical no México. Os autores mostraram que $63 \%$ das espécies estudadas tiveram períodos curtos de frutificação distribuídos nas diversas estações do ano, enquanto os outros $37 \%$ das espécies apresentaram um período mais extenso de florescimento. Piña-Rodrigues \& Piratelli (1993) acreditam que a sazonalidade de frutificação aconteça em decorrência da sazonalidade de floração, mas que devido a diferentes mecanismos de pressão seletiva os dois eventos ocorrem em épocas diferentes.

Gottsberger \& Silberbauer-Gottsberger (1983) e Oliveira \& Moreira (1992) postularam que a estratégia de frutificação de espécies do Cerrado estaria relacionada com mecanismos de dispersão. Oliveira (1991) acrescentou que, geralmente, o período de desenvolvimento de frutos é decorrente de um ajustamento entre a fenologia de florescimento e o período de dispersão com suas restrições ambientais. Variações no período de desenvolvimento e na época de maturação dos frutos também foram verificadas entre as espécies estudadas. Entre as espécies arbóreas, T. ovata (Fig. 2) apresentou longo período de desenvolvimento e curto período de maturação dos frutos, enquanto $V$. piramidalis e $T$. guianensis tiveram curtos períodos de desenvolvimento e maturação simultânea dos frutos. Da mesma forma, as espécies arbustivas $M$. chamissois e $T$. formicaria apresentaram curtos períodos de desenvolvimento e maturação dos frutos. Já a espécie $M$. pseudonervosa apresentou desenvolvimento e maturação simultâneos de frutos durante um período extenso, com variação dentro e entre indivíduos no período de maturação.

O período de maturação de frutos e sementes em uma determinada espécie parece estar relacionado não só com fatores fisiológicos como também com fatores ecológicos ligados à dispersão, 
germinação e estabelecimento de plântulas. Janzen (1983) afirma que a existência de sincronismo de maturação de frutos e sementes, tecidos genética e bioquimicamente diferentes, serve de evidência de que o período de maturação foi evolutivamente ajustado, entre outros fatores, à disponibilidade de dispersores e ocorrência de condições propícias à germinação. Piña-Rodrigues \& Aguiar (1993) distinguiram diferentes padrões de maturação de frutos relacionados com síndromes de dispersão. Entre as espécies zoocóricas foram descritos três padrões: (a) presença de frutos imaturos por período extenso, com maturação variando dentro e entre indivíduos, (b) presença de frutos imaturos por período extenso, mas com maturação rápida e simultânea no mesmo indivíduo e (c) produção abundante de frutos, maturação simultânea dentro do mesmo indivíduo e intervalos curtos entre os períodos reprodutivos.

Entre as espécies estudadas, $M$. pseudonervosa parece ter seguido o primeiro padrão, pois por um período extenso ocorreu a presença de frutos verdes e maduros num mesmo indivíduo e em outros indivíduos da população. Seria válido discutir ainda que a espécie $M$. pseudonervosa parece ser um exemplo de plantas que prolongam o período de frutificação, aumentando o tempo de exposição dos frutos aos dispersores. Tal hipótese seria reforçada pela ampla longevidade e pequena sensibilidade de suas sementes às variações de temperatura e umidade, germinando tanto na época seca e fria como na chuvosa e quente (Antunes, 1996).

O segundo padrão parece ser o caso de T. ovata, pois a permanência de frutos verdes na espécie ocorreu por um longo período (setembro/1994 a agosto/1995), enquanto o período de maturação dos frutos foi curto (junho a agosto/1995). A maturação durante a estação seca nessa espécie seria favorável à deiscência dos frutos e parte de uma estratégia reprodutiva que poderia estar associada à umidade e à temperatura do solo para a germinação das sementes na época da dispersão. Essa espécie ocorre em locais úmidos de matas de galeria inundável (Walter, 1995), e apesar de suas sementes não germinarem em anaerobiose suas plântulas toleram bem o solo encharcado (Lobo, 1993), comum na época chuvosa. A dispersão das sementes de
T. ovata concentrada na seca poderia ainda estar relacionada com oferta de alimento no arilo da semente. Tal situação reforçaria a hipótese de refúgio proporcionado aos animais pelas matas de galeria durante o período seco, como sugerido por Oliveira (1998), já que as sementes de T. ovata são dispersas por pássaros (Rodrigues, 1992).

No terceiro padrão enquadra-se a espécie T. guianensis, enquanto as espécies $T$. formicaria e $M$. chamissois parecem não se enquadrar nos padrões descritos, pois apresentaram períodos relativamente curtos de desenvolvimento e maturação dos frutos, porém a maturação não foi simultânea dentro do mesmo indivíduo. A maturação dos frutos nessas duas espécies ocorreu num curto período da transição seca-chuva (setembro a outubro/ 1994) e poderia estar associada à disponibilidade de umidade no solo para a germinação das sementes após as primeiras chuvas que, geralmente, ocorre nesse período do ano na região deste estudo. Ainda a respeito de síndromes de dispersão, Gottsberger \& Silberbauer-Gottsberger (1983) sugeriram que, nos cerrados, a maturação de frutos no período chuvoso favoreceria a dispersão, em virtude da maior quantidade e atividade de vetores animais verificados na época. Janzen (1967) já havia comentado que nesse período os frutos não só atrairiam mais seus dispersores como durariam por mais tempo. Este estudo parece corroborar com tal hipótese, uma vez que a maioria das espécies com dispersão zoocórica (T. guianensis, M. chamissois, M. pseudonervosa e $T$. formicaria) frutificou na época chuvosa.

Já no padrão descrito por Piña-Rodrigues \& Aguiar (1993) em espécies anemocóricas, a produção e maturação do fruto ocorrem em períodos mais curtos (dois a três meses). Além disso, a produção de frutos e sementes é abundante, geralmente concentrada em uma determinada época do ano e maturação dos frutos é rápida, com pouca variação dentro do mesmo indivíduo. Os mesmos autores mostraram ainda que a época de maturação e dispersão de frutos e sementes pode ocorrer no período de seca em algumas espécies como Tabebuia avellanedae, Schyzolobium parahybum, Cedrela odorata, Cedrela fissilis, Cordia trichotoma e Platypodium elegans, ou no início da estação chuvosa, como em Aspidosperma polyneuron, 
Boudichia virgilioides, Cordia alliodora, Tipuana tipu e Myroxilum balsamum. Entre as espécies, estudadas, apenas $V$. piramidalis apresentou todas as características do padrão descrito em espécies anemocóricas. A maturação dos frutos e a dispersão das sementes ocorreu no período chuvoso (fev./mar.), ocasião em que ocorre germinação imediata (Antunes, 1996). Foi observado no campo um grande número de sementes germinadas que poderia originar bancos de plântulas sob o dossel da mata.

Melhor compreensão das fenofases consideradas neste estudo dependeria de estudos complementares, que considerassem o período de observação, a inclusão de outras variáveis climáticas, edáficas e biológicas, e a relação dessas espécies com polinizadores e dispersores de frutos e sementes.

\section{CONCLUSÕES}

1. O padrão de deciduidade foliar, das árvores e arbustos estudados parece não sofrer interferência direta da ausência de chuvas no período seco.

2. De acordo com o sistema de floração as espécies $T$. guianensis e $V$. piramidalis são classificadas como atrasadas; $T$. ovata, $T$. formicaria e $M$. pseudonervosa são precoces, enquanto M. chamissois é tardia; padrão de período longo de floração é observado em $M$. pseudonervosa e T. formicaria (arbustos), e de período curto, em V. piramidalis, T. guianensis, T. ovata (árvores) e M. chamissois (arbusto).

3. Entre as espécies de dispersão zoocóricas, M. pseudonervosa apresenta frutos imaturos por período extenso, com maturação variando dentro e entre indivíduos, $T$. ovata apresenta frutos imaturos por período extenso, mas com maturação rápida e simultânea no mesmo indivíduo, enquanto T. formicaria e $M$. chamissois apresentam período relativamente curto de frutificação, porém com maturação não-simultânea dentro do mesmo indivíduo; Vochysia piramidalis apresenta o padrão de dispersão anemocórica com formação e maturação rápida dos frutos.

\section{AGRADECIMENTOS}

Ao CNPq e à Embrapa-CPAC, pelo apoio financeiro; aos funcionários da Embrapa-CPAC Nelson
O. Pais, Natália P. S. Vasquez, José F. Paixão, João B. Santos, Valdir P. Lima, Domiciano B. Silva, Márcio L. Gonçalves e Joaquim F. Silva, que auxiliaram na coleta de dados; e ao Dr. Antônio Carlos Gomes, pela análise estatística.

\section{REFERÊNCIAS}

ANTUNES, N.B. Padrões da fenologia e da germinação de seis espécies em Matas de Galeria do Distrito Federal. Brasília: UnB, 1996. 87p. Tese de Mestrado.

AOKI, H.; SANTOS, J.R. Estudo da vegetação de cerrado na área do Distrito Federal, a partir de dados orbitais. São José dos Campos: INPE, 1980. 152p. Tese de Mestrado.

ARAÚJO, G.M.; FRANCISCON, C.H.; NUNES, J.G. Fenologia de nove espécies arbóreas de um cerrado no município de Uberlândia/MG. Revista do Centro de Ciências Biomédicas da Universidade Federal de Uberlândia, Uberlândia, v.3, n.1, p.3-17, 1987.

ARRIGONI, M.F. Fenologia e germinação da casaqueira (Campomanesia rufa (Berg) Nied.): uma fruteira dos cerrados. Lavras: ESAL, 1993. 58p. Tese de Mestrado.

BARROS, M.A.G.; CALDAS, L.S. Acompanhamento de eventos fenológicos apresentados por cinco gêneros nativos do cerrado (Brasília, DF). Brasil Florestal, v.10, n.42, p.7-14, 1980.

FERRI, M.G. Ecologia dos cerrados. In: SIMPÓSIO SOBRE O CERRADO, 4., 1976, Brasília. Bases para utilização agropecuária. Belo Horizonte: Itatiaia/São Paulo: USP, 1977. p.15-33.

FOSTER, R.B. Heterogeneity and disturbance in tropical vegetation. In: SOULÉ, M.E.; WILCOX, B.A. (Eds.). Conservation biology: an evolutionary ecological perspective. Sunderland, MA: Sinauer, 1980. p.75-92.

FRANKIE, G.W.; BAKER, H.G.; OPLER, P.A. Comparative phenological studies of trees in tropical wet and dry forest in the lowlands of Costa Rica. Journal of Ecology, v.6, p.881-919, 1974a.

FRANKIE, G.W.; BAKER, H.G.; OPLER, P.A. Tropical plant phenology: applications for studies in community ecology. In: LIETH, H. Phenology and seasonality

Pesq. agropec. bras., Brasília, v.34, n.9, p.1517-1527, set. 1999 
modeling. New York: Springer-Verlag, 1974b. p.287-296. (Ecological Studies, 8).

GENTRY, A.H. Flowering phenology and diversity in tropical Bignoniaceae. Biotropica, v.6, p.64-68, 1974.

GOTTSBERGER, G.; SILBERBAUER-GOTTSBERGER, I. Dispersal and distribution in the cerrado vegetation of Brazil. Sonderbd. Naturwiss. Ver. Hamburg, v.7, p.315-352, 1983.

IBARRA-MANRÍQUEZ, G.; OYAMA, K. Ecological correlates of reprodutive traits of mexican rain forest trees. American Journal of Botany, v.79, p.383394, 1992.

JANZEN, D.H. Dispersal of seeds by vertebrate guts. In: FUTUYMA, D.; SLATKIN, M. (Eds.). Coevolution. Sunderland: Sinauer, 1983. p.232-262.

JANZEN, D.H. Ecologia vegetal nos trópicos. São Paulo: EDUSP, 1980. 79p.

JANZEN, D.H. Ecology of plants in the tropics. London: Edward Arnold, 1975. 66p.

JANZEN, D.H. Syncronization of sexual reprodution of trees during the season in Central America. Oecologia, v.67, p.40-43, 1967.

JOLY, C.A.; FELIPPE, G.M. Fenologia de Magonia pubescens St. Hil. Ciência e Cultura, v.32, p.936$941,1980$.

LIETH, H. Phenology and seasonality modeling. New York: Springer-Verlag, 1974. 444p.

LOBO, P.C. Tolerância à inundação de plantas de Talauma ovata ST. HIL. e aspectos do seu comportamento em uma Mata Ciliar da Bacia do Rio Jacaré Pepira, Brotas/SP. Campinas: UNICAMP, 1993. 98p. Tese de Mestrado.

MANTOVANI, W. Composição e similaridade florística, fenologia e espectro biológico do cerrado da Reserva Biológica de Moji Guaçu, Estado de São Paulo. Campinas: UNICAMP, 1983. Tese de Mestrado.

MANTOVANI, W.; MARTINS, F.R. Variações fenológicas das espécies do cerrado da Reserva Biológica de Moji Guaçu, Estado de São Paulo. Revista Brasileira de Botânica, v.11, p.101-112, 1988.

NG, F.S.P. Age at first flowering in dipterocarps. Malaysian Forester, v.29, p.290-295, 1966.
OLIVEIRA, P.E. Fenologia e biologia reprodutiva das espécies de Cerrado. In: SANO, S.M.; ALMEIDA, S.P. de. (Eds.). Cerrado: ambiente e flora. Planaltina: Embrapa-CPAC, 1998. p.169-192.

OLIVEIRA, P.E. The pollination and reproductive biology of a cerrado woody community in Brazil. Scotland: University of St. Andrews, 1991. 138p. Ph.D. Thesis.

OLIVEIRA, P.; GIBBS, P. Pollination biology and breeding systems of six Vochysia species (Vochysiaceae) in Central Brazil. Journal of Tropical Ecology, v.10, p.509-522, 1994.

OLIVEIRA, P.E.A.M. de; MOREIRA, A.G. Anemocoria em espécies de cerrado e mata de galeria de Brasília/ DF. Revista Brasileira de Botânica, v.15, n.2, p.163-174, 1992.

PIÑA-RODRIGUES, F.C.M.; AGUIAR, I.B. de. Maturação e dispersão de sementes. In: AGUIAR, I.B. de; PIÑA-RODRIGUES, F.C.M.; FIGLIOLIA, M.B. Sementes florestais tropicais. Brasília: ABRATES, 1993. p.215-274.

PIÑA-RODRIGUES, F.C.M.; PIRATELLI, A.J. Aspectos ecológicos da produção de sementes. In: AGUIAR, I.B. de; PIÑA-RODRIGUES, F.C.M.; FIGLIOLIA, M.B. Sementes florestais tropicais. Brasília: ABRATES, 1993. p.47-81.

RIBEIRO, J.F.; CASTRO, L.H.R. Método quantitativo para avaliar características fenológicas em árvores. Revista Brasileira de Botânica, São Paulo, v.9, n.1, p.7-11, 1986.

RIBEIRO, J.F.; GONZALES, M.I.; OLIVEIRA, P.A.M.; MELO, J.T.D. Aspectos fenológicos de espécies nativas do cerrado. In: CONGRESSO NACIONAL DE BOTÂNICA, 32., 1981, Teresina. Anais. Teresina: Sociedade Botânica do Brasil, 1982. p.181-198.

RIBEIRO, J.F.; WALTER, B.M.T. Fitofisionomias do Bioma Cerrado. In: SANO, S.M.; ALMEIDA, S.P. de (Eds.). Cerrado: ambiente e flora. Planaltina: EmbrapaCPAC, 1998. p.87-166.

RIZZO, J.A.; CENTENO, A.J.; SANTOS-LOUSA, J.; FILGUEIRAS, T.S. Levantamento de dados em áreas do cerrado e da floresta caducifólia tropical do Planalto Centro-Oeste. In: SIMPÓSIO SOBRE O CERRADO, 3., 1971, São Paulo. Anais. São Paulo: Edgard Blücher/EDUSP, 1971.p.103-109.

RODRIGUES, M.G. Sazonalidade na dieta de vertebrados frugívoros de uma floresta semidecídua 
no Brasil. Campinas: UNICAMP/Instituto de Biologia, 1992. Tese de Mestrado.

SARMIENTO, G.; MONASTÉRIO, M. Life forms and phenology. In: BOULIERE, F. (Ed.). Ecosystems of the world: Tropical Savannas. Amsterdam: Elsevier, 1983.p.79-108.

SNOW, D.W. A possible selective factor in the evolution of fruiting seasons in tropical forest. Oikos, v.15, p.274$281,1965$.

SNOW, D.W. Evolutionary aspects of fruit-eating by birds. Ibis, v.113, p.195-202, 1971.
STILES, T.G. Coadapted competitors: the flowering seasons of hummingbird-pollinated plants in a tropical forest. Science, v.198, p.1177-1178, 1977.

STILES, E.W. Patterns of fruit presentation and seed dispersal in bird disseminated woody plants in the eastern decidous forest. American Naturalist, v.116, p.670-688, 1980.

WALTER, B.M.T. Distribuição espacial de espécies perenes em uma mata de galeria inundável no Distrito Federal; florística e fitossociologia. Brasília: UnB, 1995. 200p. Tese de Mestrado. 